\title{
Regular inhaled corticosteroids in adult-onset asthma and the risk for future cancer:a population-based cohort study with proper person-time analysis
}

\author{
This article was published in the following Dove Press journal: \\ Therapeutics and Clinical Risk Management \\ 26 March 2015 \\ Number of times this article has been viewed
}

\author{
Victor C Kok ${ }^{1,2}$ \\ Jorng-Tzong Horng 2,3 \\ Hsu-Kai Huang ${ }^{3}$ \\ Tsung-Ming Chao ${ }^{4}$ \\ Ya-Fang Hong ${ }^{5}$ \\ 'Division of Medical Oncology, \\ Department of Internal Medicine, \\ Kuang Tien General Hospital, Taichung, \\ Taiwan; ${ }^{2}$ Department of Biomedical \\ Informatics, Asia University Taiwan, \\ Taichung, Taiwan; ${ }^{3}$ Department of \\ Computer Science and Information \\ Engineering, National Central \\ University, Jhongli, Taiwan; ${ }^{4}$ Statistics \\ Unit, Department of Applied \\ Geomatics, Chien Hsin University, \\ Jhongli, Taiwan; ${ }^{5}$ Institute of Molecular \\ Biology, Academia Sinica, Nankang, \\ Taipei, Taiwan
}

Background: Recent studies have shown that inhaled corticosteroids (ICS) can exert anti-inflammatory effects for chronic airway diseases, and several observational studies suggest that they play a role as cancer chemopreventive agents, particularly against lung cancer. We aimed to examine whether regular ICS use was associated with a reduced risk for future malignancy in patients with newly diagnosed adult-onset asthma.

Methods: We used a population-based cohort study between 2001 and 2008 with appropriate person-time analysis. Participants were followed up until the first incident of cancer, death, or to the end of 2008. The Cox model was used to derive an adjusted hazard ratio (aHR) for cancer development. Kaplan-Meier cancer-free survival curves of two groups were compared.

Results: The exposed group of 2,117 regular ICS users and the nonexposed group of 17,732 non-ICS users were assembled. After 7,365 (mean, 3.5 years; standard deviation 2.1) and 73,789 (mean, 4.1 years; standard deviation 2.4) person-years of follow-up for the ICS users and the comparator group of non-ICS users, respectively, the aHR for overall cancer was nonsignificantly elevated at 1.33 with $95 \%$ confidence interval (CI), 1.00-1.76, $P=0.0501$. The KaplanMeier curves for overall cancer-free proportions of both groups were not significant (log-rank, $P=0.065$ ). Synergistic interaction of concurrent presence of regular ICS use was conducted using "ICS-negative and chronic obstructive pulmonary disease (COPD)-negative" as the reference. The aHR for the group of "ICS-positive, COPD-negative" did not reach statistically significant levels with aHR at 1.38 (95\% CI, 0.53-3.56). There was a statistically significant synergistic interaction of concurrent presence of regular ICS use and COPD with aHR at 3.78 (95\% CI, 2.10-6.81).

Conclusion: The protective effect of regular ICS use in the studied East Asian patients with adult-onset asthma was not detectable, contrary to reports of previous studies that ICS might prevent the occurrence of future cancer.

Keywords: immortal time bias, NHIRD, population-based study, retrospective cohort study, risk of cancer

\section{Background}

Inhaled corticosteroids (ICS) are regarded as the most effective topical anti-inflammatory drugs for treating chronic airway diseases, including asthma and chronic obstructive pulmonary disease (COPD). The mechanism of action of ICS is mainly attributed to their anti-inflammatory effects exerted on the bronchial lining cells. It has been demonstrated that ICS can exert their beneficial anti-inflammatory effects by inhibiting the synthesis of leukotriene C4 and prostaglandin D2 in the airway, reducing serum
Jorng-Tzong Horng

National Central University, 300 Jhongda

Road, Jhongli, Taoyuan 3200I, Taiwan

Tel +886919057555

Email horng@db.csie.ncu.edu.tw 
surfactant protein D level, and significantly decreasing the proinflammatory bacterial lipopolysaccharide-induced interleukins (IL) such as IL-1 beta, IL-6, and IL-8, as well as tissue necrotic factor-alpha secretion. ${ }^{1-4}$

The initial suggestion for the property of cancer prevention by ICS came from an animal study that demonstrated that in female A/J mice, ICS could inhibit the formation of pulmonary adenomas. ${ }^{5}$ Subsequently, a small, randomized, placebo-controlled, Phase IIb clinical study suggested that inhaled budesonide decreases the proportion of lung nodules in smokers with bronchial dysplasia as detected by spiral computerized tomography $(P=0.024),{ }^{6}$ a second randomized, placebo-controlled, Phase IIb clinical study showed a trend toward regression of ground glass opacities. ${ }^{6,7}$

The cancer prevention property of ICS has been addressed in COPD populations in the following three clinical studies. A population-based cohort study on ICS for COPD revealed that there was a dose-dependent decreased risk of lung cancer associated with ICS (ICS dose $<1,200 \mu \mathrm{g}$ /day, the adjusted hazard ratio [aHR] was 1.3 with $95 \%$ confidence interval [CI], 0.67-1.90; whereas, when ICS dose $\geq 1,200 \mu \mathrm{g} /$ day, aHR was 0.39 with $95 \%$ CI, $0.16-0.96) .{ }^{8}$ In a populationbased nested case-control study among COPD patients who had quit smoking, the multivariate aHR for lung cancer development was 0.64 (95\% CI, 0.42-0.98) in ICS users compared with short-acting bronchodilator users; moreover, a dose-responsive relationship was observed. ${ }^{9}$ In a proof-ofconcept randomized controlled study in a COPD cohort of 36 patients evaluating markers in epithelial-mesenchymal transition (EMT) in large airway samples, the active treatment arm with ICS had statistically significantly regressed some EMT biomarkers. ${ }^{10}$ This pilot study provided suggestive support for an anti-EMT effect of ICS in the large airways in patients with COPD.

Likewise, there are at least two observational studies that assessed cancer prevention by ICS in asthmatic populations in literature. A population-based nested case-control study in adult Korean patients with ICS disclosed that the adjusted odds ratio (OR) for lung cancer was 0.79 with $95 \%$ CI, 0.69-0.90, whereas there was no statistically significant association of the risk for laryngeal cancer. ${ }^{11}$ It should be noted that nearly $58 \%$ of the lung cancer cases included in this Korean study had COPD.

A substudy to assess the association of ICS use and future cancer death in female COPD-free asthmatics $(n=2,671)$ in the Nurses' Health Study, a longitudinal observational study in the United States, demonstrated no decrease in the number of cancer deaths among ICS users (OR $=0.66 ; 95 \%$
CI, 0.32-1.38). ${ }^{12}$ The ORs for cancer death were adjusted for age, smoking, severity of asthma, heart disease, stroke, and medication, including aspirin and statin. The OR for death from cancer would have been significantly reduced if ICS use was associated with a significant reduction of lung cancer cases because lung cancer patients typically have a high mortality rate.

Adult-onset asthma differs from asthma originating from childhood in several respects. Adult-onset asthma mainly affects women and it is nonatopic. Patients with adult-onset asthma have a more severe disease, and tend to associate with a faster decline in lung function. ${ }^{13,14}$ Therefore, regular ICS use is mostly required in this group of patients.

We thus wanted to use a population-based retrospective cohort study design to examine whether regular use of ICS would offer beneficial effects in terms of a reduced risk for future occurrence of cancers, particularly lung cancer, in patients with adult-onset asthma. Unlike a nested case-control study design that is suitable for overcoming the time-varying nature of treatment, we approached this issue using a cohort study design with the proper person-time approach. ${ }^{15-19}$

\section{Materials and methods \\ Data source}

This study to examine the hypothesis that regular ICS use in patients with adult-onset asthma provides protective effects from future cancer development used a population-based retrospective cohort design with selected datasets derived from the National Health Insurance Research Database (NHIRD) provided to scientists in Taiwan for research purposes. The National Health Insurance program of Taiwan was established in 1995. As of 2007, more than $98 \%$ of the residents in Taiwan are enrolled into this single-payer program.

Combining data from the registration files and original claim data in the NHIRD, specific data subsets were constructed by the experts of the NHIRD for research purposes. This study utilized the Longitudinal Health Insurance Dataset 2000, which consists of one million randomly selected enrollees sampled from the Registry for Beneficiaries in the year 2000. This dataset was checked against the original NHIRD for accurate representation to confirm that there was no significant difference in the distribution of sex (chi-square $=1.74$, degrees of freedom $=1, P=0.187$ ) between individuals in the Longitudinal Health Insurance Dataset 2000 and the mother database, NHIRD. ${ }^{20}$ The authors have previously performed several population-based cohort studies using data or datasets from the NHIRD. ${ }^{21-23}$

This study was conducted after approval by the Kuang Tien General Hospital Institutional Review Board with a 
Certificate of Approval, numbered IRB-10323. Written informed consent was not obtained because patient records were anonymized and de-identified prior to analysis.

\section{Study cohorts}

The target population for this research was ambulatory patients with asthma who were available to participate from 2001 to 2008 . The inclusion criteria were adult patients with a new International Classification of Diseases, Ninth Edition, with Clinical Modification (ICD-9-CM) diagnosis of asthma (493.xx) in the period from January 1, 2001 to December 31, 2008, with medical claims at least three times a year. The first claim of asthma was the index date. Exclusion criteria included missing data (null value), age less than 20 , presence of asthma before 2001, ICS use before the diagnosis of asthma, fewer than three claims per annum for asthma encounters, and prevalent cancer before the index date. A period of at least 1 year before the index date was used to rule out exclusion criteria.

The study cohort consisted of regular ICS users. The patients identified as regular ICS users were those with an average of six or more prescriptions of ICS per year after the index date. The day of the first prescription of ICS was the index date. The immune time before the use of ICS was reallocated to the non-ICS group to overcome the immune (immortal) time bias. The remainder of the patients with adult-onset asthma, who received no ICS treatment throughout the follow-up period, were assembled as the comparator cohort (non-ICS user cohort). Studied patients could not cross over between groups once allocation to either ICS users group or non-ICS users group was determined (Figure 1).

\section{Collection of data on comorbidities and treatment}

Basic demographic data such as age, sex, and smokingrelated diagnosis as a surrogate for cigarette-smoking history were collected using ICD-9-CM codes 305.1, 491.0, 491.2, 492.8, 496, 523.6, 649.0, 989.84, and V15.82. The confounding medical comorbidities included in the study were allergic rhinitis, atopic dermatitis, rhinosinusitis, COPD, diabetes mellitus (DM), depression, gastroesophageal reflux disease (GERD), osteoporosis, hypertension, heart failure, dyslipidemia, arrhythmia, and ischemic heart disease, each of which has its own corresponding ICD-9-CM code/codes. In addition, the Charlson comorbidity index (CCI) was calculated for each patient in both groups. Baseline characteristics (comorbidities) for non-ICS users were looked for and determined in the preceding 1 year pre-index period.
The pre-index period used to define baseline characteristics for regular ICS users was the preceding 1 year before the initiation of ICS prescription. We excluded diabetes, myocardial infarction, and congestive heart failure from the CCI score calculation because these diseases/conditions were preplanned collected comorbidities. The CCI score from zero to above five can provide information on the severity of concurrent illnesses in a patient.

Three types of ICS were available in the region in the study period: beclomethasone dipropionate, budesonide, and fluticasone propionate. An average daily dose of an ICS as an equivalent dose of triamcinolone acetonide, based upon the estimated equipotent therapeutic index of the ICS for adults, was calculated by dividing the total number of micrograms by the number of days prescribed during the follow-up period. ${ }^{24}$ Other asthmatic medications included for analyses in this study were long-acting bronchodilators, short-acting bronchodilators, leukotriene receptor antagonists, theophylline, and oral corticosteroids.

\section{Study end-points, outcome measures, and follow-up}

Both groups of patients were followed up until the development of the first malignancy, death, or the end of the year in 2008, whichever came first. The outcome measure was the adjusted risk of incident malignancy using a multivariate hazard ratio in the Cox model. The cancers looked at in this cohort study were oral, lung, esophageal, gastric, urinary bladder, prostatic, colorectal, hepatic, non-melanocytic skin, nasopharyngeal, and female breast cancers.

\section{Statistical analyses}

Person-year values were all calculated with the proper person-time approach to overcome the immortal time bias. An incidence rate ratio (IRR) (the ratio of two incidence rates for cancer development) comparing the exposed and nonexposed groups with person-time denominators along with a 95\% CI was constructed by Poisson distribution and test-based methods. The Kaplan-Meier model was used to estimate various cancer-free proportions of ICS regular users and non-ICS users, and the log-rank test was carried out to compare the two curves. The two-sided alpha level of 0.05 was adopted. A Cox proportional hazards regression model was constructed to control for sex, age group, CCI group, all comorbidities mentioned earlier, smoking-related diagnoses, and all other asthma medications. Sensitivity analysis was conducted using a synergy index, calculated as: 


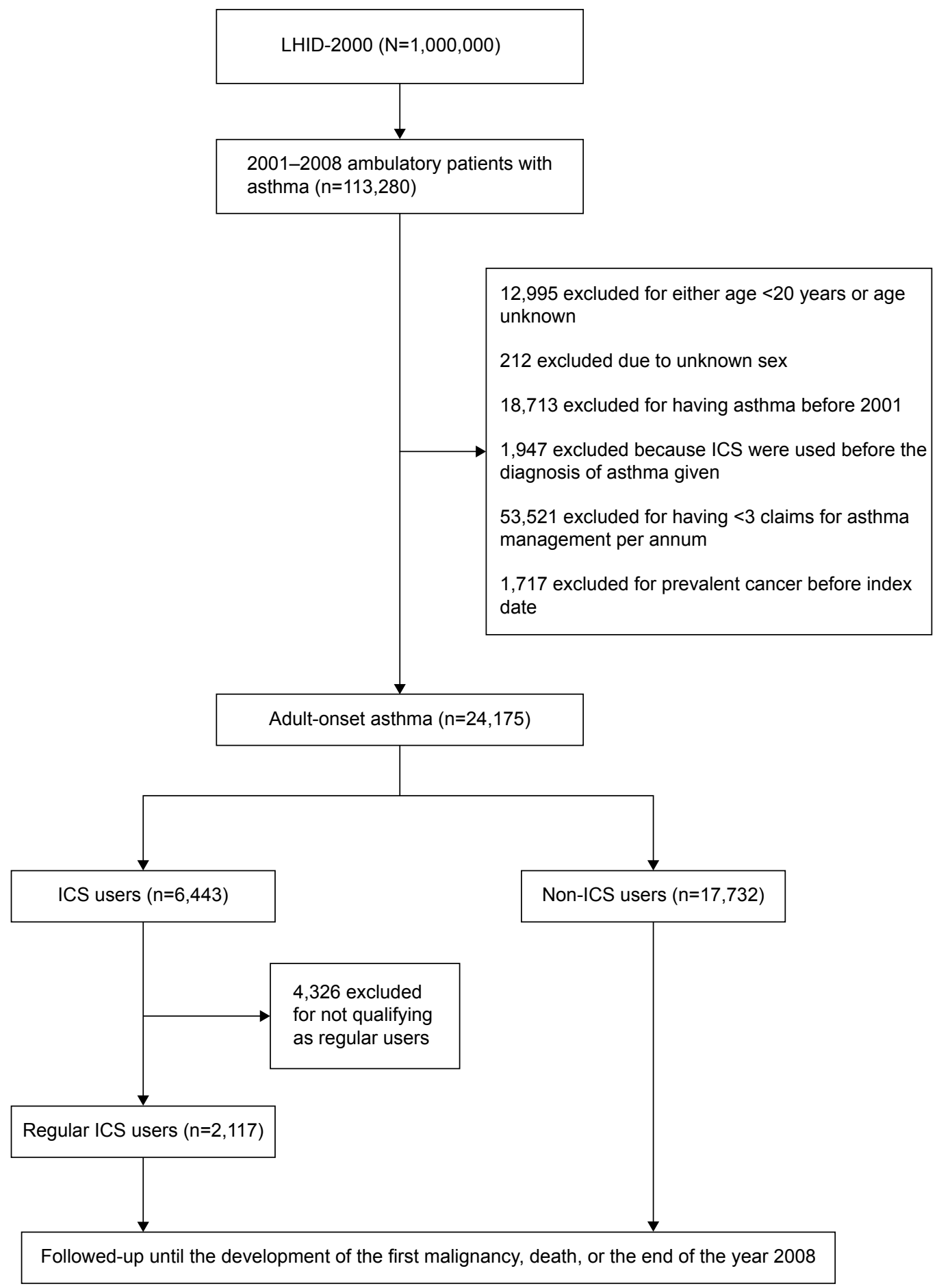

Figure I The study flow diagram showing the study design using a population-based retrospective cohort study and the assembling of the ICS cohort and the comparator non-ICS use cohort.

Abbreviations: ICS, inhaled corticosteroids; LHID, Longitudinal Health Insurance Database.

$$
\left(\mathrm{HR}_{\mathrm{AB}}-1\right) /\left(\mathrm{HR}_{\mathrm{A}}+\mathrm{HR}_{\mathrm{B}}-2\right)
$$

(1) A and B are present; when the synergy index is larger than 1 , a synergistic interaction exists. The CI estimation of the with $\mathrm{HR}_{\mathrm{A}}$ and $\mathrm{HR}_{\mathrm{B}}$ representing hazard ratios for two dichotomous factors, $\mathrm{A}$ and $\mathrm{B}$, respectively, and $\mathrm{HR}_{\mathrm{AB}}$ representing the hazard ratio for future cancer development if factors interaction is estimated according to Hosmer and Lemeshow's method. ${ }^{25}$ We used SAS statistical software version 9.2 for the statistical analyses. 


\section{Results and discussion}

The entire cohort of 24,175 cancer-free individuals with newly diagnosed adult-onset asthma from 2001 to 2008 was studied. The exposed group consisting of 2,117 regular users of ICS and the non-exposed comparator group of 17,732 non-ICS users were assembled from the cohort (Figure 1). After 7,365 person-years of follow-up (mean, 3.5 years; standard deviation 2.1), 130 incident cancers had occurred for the ICS users. In comparison, 1,064 incident cancers had occurred in the comparator group of non-ICS users after 73,789 person-years' follow-up (mean, 4.1 years; standard deviation 2.4).

The mean age of the patients in both groups was similar at approximately 53 years. There were more women than men with $50.31 \%$ females among the regular ICS users group and $54.27 \%$ in the non-ICS users group. Sixty-three percent and $43 \%$ were cigarette smokers in the ICS users group and non-ICS users group, respectively (Table 1).

DM (approximately 18\%), hypertension (40\%), dyslipidemia $(14 \%)$, and coronary heart disease (23\%) were similar in both groups of patients. The proportion of depression was less than $2 \%$, and that of osteoporosis approximately $3 \%$; these were also quite similar between both groups. However, the regular ICS users group had higher proportions of allergic rhinitis (53\% versus $35 \%$ ) and COPD (58\% versus $40 \%$ ) (Table 1$)$.

The unadjusted IRR for future cancer occurrence was significantly elevated in all regular ICS users as a whole with the IRR at $1.22(95 \% \mathrm{CI}, 1.02-1.47)$. In addition, IRR statistically increased in the age group of 60-79 years (IRR 1.27, 95\% CI, 1.00-1.61); the group of patients with CCI score 1 or 2 (IRR 1.36, 95\% CI, 1.06-1.75); patients without atopic dermatitis (IRR 1.21, 95\% CI, 1.00-1.46); patients with COPD (IRR 1.35, 95\% CI, 1.09-1.67); patients without DM (IRR 1.24, 95\% CI, 1.01-1.52); patients with depression (IRR 4.36, 95\% CI, 1.55-12.20); patients without GERD (IRR 1.22, 95\% CI, 1.02-1.47); patients without osteoporosis (IRR $1.22,95 \%$ CI, 1.01-1.47); patients with heart failure (IRR 1.91, 95\% CI, 1.23-2.94); patients with dyslipidemia (IRR $1.67,95 \%$ CI, 1.10-2.52); patients without rhinosinusitis (IRR 1.21, 95\% CI, 1.00-1.46); patients with cardiac arrhythmia (IRR 1.81, 95\% CI, 1.26-2.62); patients with coronary heart disease (IRR 1.69, 95\% CI, 1.27-2.26); patients who took theophylline (IRR 1.43, 95\% CI, 1.151.78); and patients with smoking-related diagnoses (IRR 1.34, 95\% CI, 1.04-1.71) (Table S1).

After controlling the differences in sex, age group, $\mathrm{CCI}$ score, all comorbidities, smoking-related diagnoses, and all
Table I Baseline characteristics and follow-up data for both groups of adult-onset asthmatics receiving ICS regularly or without the ICS use

\begin{tabular}{|c|c|c|}
\hline & Regular ICS users & Non-ICS users \\
\hline Adult-onset asthmatics & 2,117 & 17,732 \\
\hline Age (years), mean (SD) & $52.8(17.6)$ & $53.3(18.2)$ \\
\hline \multicolumn{3}{|l|}{ Age group } \\
\hline $20-39$ & $564(26.64)$ & $4,634(26.13)$ \\
\hline $40-59$ & $734(34.67)$ & $6,060(34.18)$ \\
\hline $60-79$ & $710(33.54)$ & $5,7 \mid I(32.2 I)$ \\
\hline$\geq 80$ & $109(5.15)$ & I,327 (7.48) \\
\hline \multicolumn{3}{|l|}{ Sex } \\
\hline Man & I,052 (49.69) & $8,108(45.73)$ \\
\hline Woman & $\mathrm{I}, 065(50.3 \mathrm{I})$ & $9,624(54.27)$ \\
\hline Smoking-related diagnoses* & $1,324(62.54)$ & $7,566(42.67)$ \\
\hline \multicolumn{3}{|l|}{ Comorbidities } \\
\hline Allergic rhinitis & $\mathrm{I}, \mid 3 \mathrm{I}(53.42)$ & $6,221(35.08)$ \\
\hline Atopic dermatitis & I $44(6.80)$ & $\mathrm{I}, 04 \mathrm{I}(5.87)$ \\
\hline Rhinosinusitis & $146(6.90)$ & $802(4.52)$ \\
\hline COPD & $1,230(58.10)$ & 7,047 (39.74) \\
\hline DM & $377(\mid 7.8 I)$ & $3,324(18.75)$ \\
\hline Depression & $34(1.6 \mathrm{I})$ & $312(1.76)$ \\
\hline GERD & $32(1.5 \mathrm{I})$ & $89(0.50)$ \\
\hline Osteoporosis & $72(3.40)$ & $573(3.23)$ \\
\hline Hypertension & $88 \mid(41.62)$ & $7,061(39.82)$ \\
\hline Heart failure & $209(9.87)$ & I,353 (7.63) \\
\hline Dyslipidemia & $311(14.69)$ & $2,514(14.18)$ \\
\hline Arrhythmia & $308(14.55)$ & $2,279(12.85)$ \\
\hline $\mathrm{CHD}$ & $488(23.05)$ & $3,983(22.46)$ \\
\hline $\mathrm{CCl}$ score, mean (SD) & $0.93(1.20)$ & $0.98(1.25)$ \\
\hline \multicolumn{3}{|l|}{$\mathrm{CCl}$ group } \\
\hline $\mathrm{CCl}$ score 0 & $992(46.86)$ & $829(46.76)$ \\
\hline $\mathrm{CCl}$ score $\mathrm{I}, 2$ & $919(43.4 I)$ & $7,462(42.08)$ \\
\hline $\mathrm{CCl}$ score 3,4 & I $77(8.36)$ & I,608 (9.07) \\
\hline $\mathrm{CCl}$ score $\geq 5$ & $29(1.37)$ & 371 (2.09) \\
\hline \multicolumn{3}{|l|}{ Type of ICS } \\
\hline $\begin{array}{l}\text { Beclomethasone } \\
\text { dipropionate }\end{array}$ & $144(6.80)$ & NA \\
\hline Budesonide & I,298 (6I.3I) & NA \\
\hline Fluticasone propionate & $\mathrm{I}, 070(50.54)$ & NA \\
\hline \multicolumn{3}{|l|}{ Other asthma medication } \\
\hline LABA & $1,369(64.67)$ & $10(0.06)$ \\
\hline SABA & $284(13.42)$ & $355(2.00)$ \\
\hline LTRA & $285(13.46)$ & $239(1.35)$ \\
\hline Theophylline & $\mathrm{I}, 243(58.72)$ & $7,945(44.8 I)$ \\
\hline OCS & 421 (19.89) & $2,031(11.45)$ \\
\hline $\begin{array}{l}\text { Follow-up (years), } \\
\text { mean (SD) }\end{array}$ & $3.5(2.1)$ & $4.1(2.4)$ \\
\hline \multicolumn{3}{|l|}{ Follow-up duration (years) } \\
\hline$\leq \mathrm{I}$ & $320(15.12)$ & $2,303(12.99)$ \\
\hline $\mathrm{I}-3$ & $630(29.76)$ & $4,291(24.20)$ \\
\hline $3-5$ & $604(28.53)$ & $4,252(23.98)$ \\
\hline $5-7$ & $429(20.26)$ & $4,26 I(24.03)$ \\
\hline$\geq 7$ & $134(6.33)$ & $2,625(14.80)$ \\
\hline
\end{tabular}

Notes: Values listed as number (\%) unless otherwise stated. *Included all cases of COPD.

Abbreviations: $\mathrm{CCl}$, Charlson comorbidity index; $\mathrm{CHD}$, coronary heart disease; COPD, chronic obstructive pulmonary disease; DM, diabetes mellitus; GERD, gastroesophageal reflux disease; ICS, inhaled corticosteroids; LABA, long-acting inhaled beta-agonist; LTRA, leukotriene receptor antagonist; NA, not applicable; OCS, oral corticosteroid; SABA, short-acting beta-agonist; SD, standard deviation. 
Table 2 Number of incident malignancies in each cohort and the adjusted hazard ratios with their $95 \%$ confidence interval for specific sites of cancer associated with regular ICS treatments using non-ICS users as the reference

\begin{tabular}{|c|c|c|c|c|}
\hline Cancer site & ICS users & Non-ICS users & Adjusted HR (95\% CI)* & $P$-value \\
\hline Person-years ${ }^{\ddagger}$ & $7,364.96$ & $73,788.86$ & & \\
\hline Overall & 130 & 1,064 & $1.33(1.00-1.76)$ & 0.0501 \\
\hline Oral & 7 & 43 & $2.64(0.92-7.62)$ & 0.0717 \\
\hline Lung & 36 & 200 & $2.23(1.31-3.79)$ & 0.0031 \\
\hline Esophagus & 0 & 22 & - & - \\
\hline Stomach & 2 & 47 & $0.08(0.0 \mathrm{I}-2.86)$ & 0.1670 \\
\hline Urinary bladder & 5 & 28 & $\mathrm{I} .03(0.14-7.4 \mathrm{I})$ & 0.9806 \\
\hline Prostate & 9 & 52 & $1.98(0.70-5.57)$ & 0.1967 \\
\hline Colorectal & 23 & 168 & I.3I (0.65-2.64) & 0.4569 \\
\hline Liver & 11 & $14 \mid$ & $0.89(0.33-2.37)$ & $0.8|4|$ \\
\hline Skin, NMSC & 5 & 25 & $0.18(0.01-7.55)$ & 0.3703 \\
\hline Nasopharynx & 2 & 22 & $1.99(0.45-8.85)$ & 0.3649 \\
\hline Female breast & 8 & 46 & $1.88(0.58-6.07)$ & 0.2899 \\
\hline
\end{tabular}

Notes: *Adjusted using the Cox model for sex, age group, Charlson comorbidity index group, all comorbidities, smoking-related diagnoses, and all other asthma medications. Person-year values were all calculated with the proper person-time approach avoiding the immortal time bias. *For female breast cancer, the respective person-years was 3,695.45 for the ICS users and 40,295.94 for non-ICS users. Bold type indicates statistical significance.

Abbreviations: $\mathrm{Cl}$, confidence interval; HR, hazard ratio; ICS, inhaled corticosteroids; NMSC, non-melanocytic skin cancer.

asthma medications other than ICS in the Cox proportional hazards regression model on the risk of cancer development using non-ICS users as the reference, the aHR for overall cancer was statistically nonsignificant at 1.33 with $95 \% \mathrm{CI}$, 1.00-1.76, $P=0.0501$ (Table 2). The Kaplan-Meier model for estimating the overall cancer-free proportions were not significant with the log-rank test $P=0.065$ (Figure 2A). Likewise, the risk in terms of aHRs were nonsignificant in oral (aHR $=2.64,95 \%$ CI, 0.92-7.62), esophageal, gastric ( $\mathrm{aHR}=0.08,95 \% \mathrm{CI}, 0.01-2.86)$, urinary bladder $(\mathrm{aHR}=1.03$, 95\% CI, 0.14-7.41), prostatic (aHR $=1.98,95 \%$ CI, 0.70 5.57), colorectal (aHR $=1.31,95 \% \mathrm{CI}, 0.65-2.64$ ), liver (aHR $=0.89,95 \%$ CI, 0.33-2.37), non-melanocytic skin ( $\mathrm{aHR}=0.18,95 \% \mathrm{CI}, 0.01-7.55)$, nasopharyngeal $(\mathrm{aHR}=1.99$, 95\% CI, 0.45-8.85), and female breast cancers (aHR $=1.88$, 95\% CI, 0.58-6.07) (Table 2). Nevertheless, the aHR for lung cancer was elevated at 2.23 (95\% CI, 1.31-3.79) in an ICS individual as compared with non-ICS users. Figure 2B shows that the Kaplan-Meier curves of lung cancer-specific cancerfree proportions in ICS regular users versus non-ICS users were statistically significantly different under the log-rank test with $P=0.0035$. An ICS dose-responsive relationship was examined by separating patients into two groups by the daily ICS dose at a cut-off of $1,500 \mu \mathrm{g} /$ day and 2,000 $\mu \mathrm{g} /$ day, respectively. Both analyses showed no statistical significance when comparing ICS doses below or above these cut-offs (Figure 2C and D).

\section{Sensitivity analysis}

Because $58.1 \%$ and $63 \%$ of the regular ICS users had COPD and smoking-related diagnoses, respectively, and these figures were obviously higher than those of non-ICS users, we decided to examine the synergistic interactions between the state of having regular ICS use and the presence of COPD comorbidity. Using ICS-negative and COPD-negative as the reference, the aHR for the group of regular ICS users who did not have COPD (ICS-positive, COPD-negative) did not reach statistically significant levels with aHR at 1.38 (95\% CI, 0.53-3.56). Nevertheless, there was a statistically significant synergistic interaction of the concurrent presence of regular ICS use and COPD with aHR at 3.78 (95\% CI, 2.10-6.81) (Table 3).

\section{Discussion}

Using a population-based cohort study design with proper person-time analysis to investigate whether the antiinflammatory effects of ICS might reduce the risk for future cancer, particularly in the lungs, the results of our study revealed no beneficial association between regular ICS use for adult-onset asthma and future malignancy development. The exposed group had 2,117 patients and the comparator group almost 18,000 patients. These are cohorts large enough for cancer epidemiological assessment. In addition to sex and age, the Cox model also controls for the CCI, smoking-related diagnostic group as a surrogate for the status of cigarette smoking, atopic dermatitis, COPD, DM, depression, GERD, dyslipidemia, other medical comorbidities, and asthma medications other than ICS such as long-acting bronchodilators, short-acting bronchodilators, leukotriene receptor antagonists, theophylline, and oral steroids.

The immortal time bias was avoided by the preplanned proper person-time approach to reallocate the "immortal 

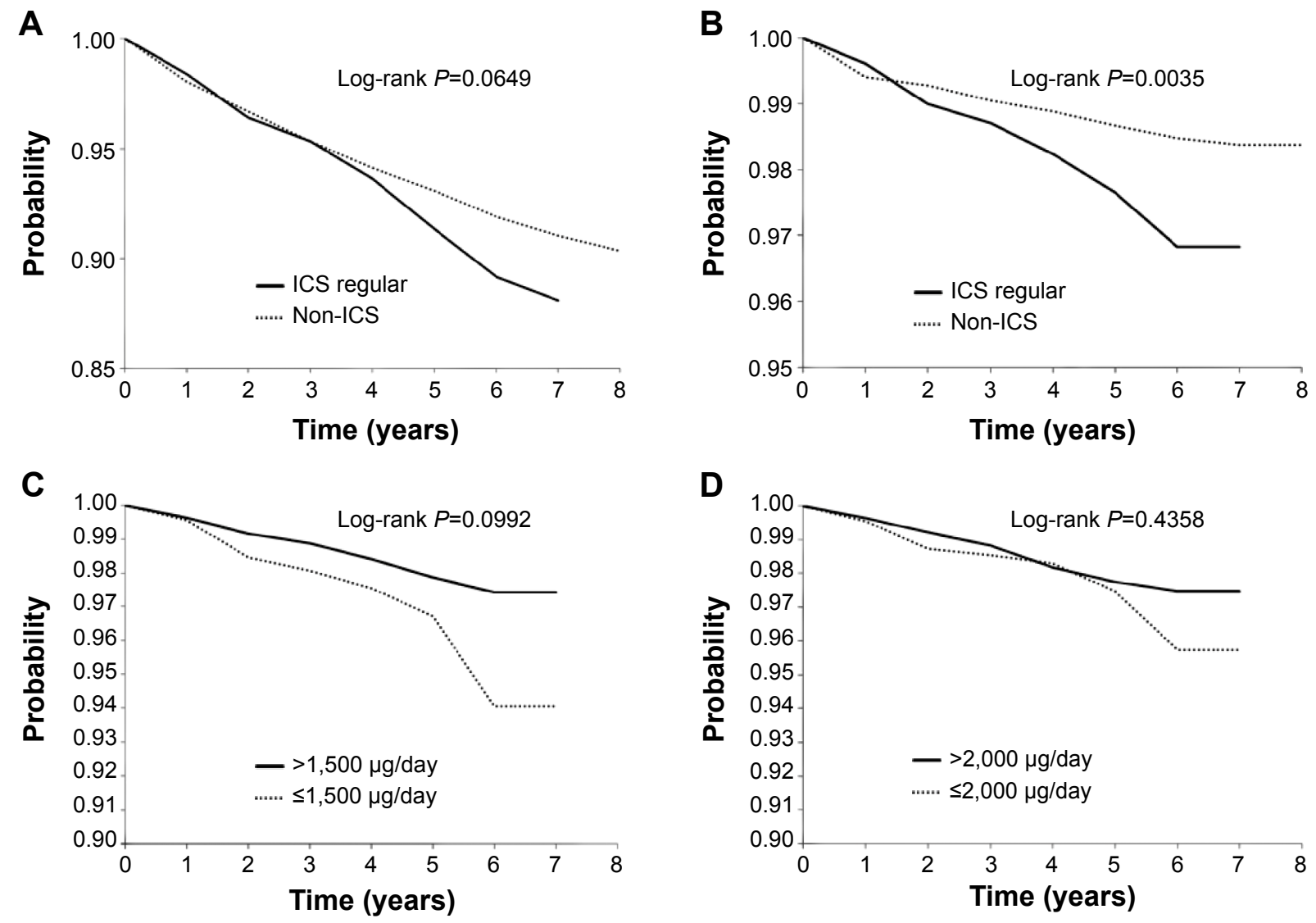

Figure 2 Comparison of either overall cancer or lung cancer-specific Kaplan-Meier survival curves between ICS users and non-users or using different cut-offs of the ICS dosage.

Notes: (A) Kaplan-Meier model for estimating the overall cancer-free proportions of ICS regular users and non-ICS users with the proper person-time approach. (B) Kaplan-Meier model for estimating the lung cancer-specific cancer-free proportions in ICS regular users versus non-ICS users with the proper person-time approach. (C) Kaplan-Meier model for estimating the lung cancer-free proportions by ICS dosage at I,500 $\mu \mathrm{g}$ per day among ICS regular users with the proper person-time approach. (D) Kaplan-Meier model for estimating the lung cancer-free proportions by ICS dosage at 2,000 $\mu \mathrm{g}$ per day among ICS regular users with the proper person-time approach.

Abbreviation: ICS, inhaled corticosteroids.

time" before starting an ICS in the exposed group to the non-exposed group. There is no potential for selection bias because in this study, a patient with adult-onset asthma who was prescribed an ICS remained during the entire follow-up duration in the exposed group. In other words, no cross-over between the studied groups was allowed. Recall bias, commonly present in cohort studies adopting patient self-reported asthma, was not present in this study. This study applied very strict criteria of case ascertainment that excluded patients having less than three claims for asthma management per year before the study group was assembled.

A recent study by South Korean colleagues using a population-based nested case-control study design showed that there was a protective effect against lung cancer but not

Table 3 Synergistic interactions between ICS regular use and COPD comorbidity on the risk of lung cancer development in patients with adult-onset asthma

\begin{tabular}{lllll}
\hline & Crude HR (95\% Cl) & SI (95\% Cl) & Adjusted HR (95\% CI) & SI (95\% CI) \\
\hline ICS (-ive), COPD (-ive) & 1.00 & $2.88(1.003-8.24)$ & 1.00 & $3.88(0.75-20.13)$ \\
ICS (+ive), COPD (-ive) & $0.79(0.32-1.94)$ & & $1.38(0.53-3.56)$ & $1.44(1.08-1.92)^{*}$ \\
ICS (-ive), COPD (+ive) & $2.14(1.62-2.83)^{*}$ & & $3.78(2.10-6.8 I)^{*}$ & \\
ICS (+ive), COPD (+ive) & $3.67(2.43-5.53)^{*}$ & & & \\
\hline
\end{tabular}

Notes: $* P<0.05$. The hazard ratios were adjusted for Charlson comorbidity index, allergic rhinitis, atopic dermatitis, rhinosinusitis, diabetes mellitus, depression, gastroesophageal reflux disease, osteoporosis, hypertension, heart failure, dyslipidemia, arrhythmia, and ischemic heart disease. Synergy index is calculated as $\left(H R_{A B}-1\right) /$ $\left(H R_{A}+H R_{B}-2\right)$; when the synergy index is larger than I, a synergistic interaction exists. ${ }^{25}$

Abbreviations: -ive, negative; +ive, positive; Cl, confidence interval; COPD, chronic obstructive pulmonary disease; HR, hazard ratio; ICS, inhaled corticosteroids; SI, synergy index. 
laryngeal cancer with ICS use versus non-use with an adjusted OR at 0.86 (95\% CI, 0.8-0.93). ${ }^{11}$ The main differences between their study and ours were (aside from the difference in the study design) different target population (adult users of ICS in the Korean study were not limited to those with adult-onset asthma) and having no smoking-related diagnoses, DM, depression, and other medical comorbidities in the covariate adjustment in their model. In terms of the weight of evidence level, the evidence from a cohort study design is higher than a nested case-control study design.

In contrast to prior studies, our study demonstrates that ICS use in a subgroup of patients with concurrent COPD will raise the risk for lung cancer with an aHR at 3.78 (95\% CI, 2.10-6.81) as compared with the subgroup of patients with concurrent COPD but with no ICS use (aHR 1.44, 95\% CI 1.08-1.92). This result is unique because the results of previous observational studies pointed in the opposite direction..$^{8,9}$ Therefore, the issue of whether ICS can prevent lung cancer or not still remains to be investigated.

How frequent is the coexistence of adult-onset asthma and COPD in an administrative database setting? In a retrospective population-based cohort study using Medicaid administrative data, Shaya el al reported that $46 \%$ of the asthma population carried a concomitant COPD diagnosis and thus the study gave a good estimate on the prevalence of coexisting asthma and COPD in the United States. ${ }^{26,27}$ Fairly similarly, our study using NHIRD data shows that rate of concomitant asthma-COPD disease is around $49 \%$ in the entire cohort of adult-onset asthma (Table 1). Although misclassification bias is potentially present in any of the above administrative claims database research, the authors would regard it as the real world data.

This study also provides a glimpse into the characteristics of this cohort of adult-onset asthma. The mean age is approximately 53 years, females account for up to $54 \%$ of the patients, and there is a low frequency of atopic dermatitis, at approximately $6 \%$. In literature, adult-onset asthma has female preponderance, decreasing incidence with older age, and more severe disease as compared with childhood-onset asthma. $^{13,14,28,29}$

To suggest to our patients that the use of ICS may provide some protection against future lung cancer will create a false sense of security in patients with COPD, a well-known risk factor for lung cancer. Our study results have refuted the presence of any beneficial effects on cancer development; therefore, personalized management of patients with adult-onset asthma should avoid consideration of the prior use of ICS.

\section{Limitations of the study}

There are some notable limitations of the study. Although a physician-diagnosed adult-onset asthma is better than a self-reported one, a wrongly given ICD-9-CM diagnosis can happen, theoretically, which may result in misclassification bias. In this cohort study, the authors did not consider the impact of the patients' socioeconomic status, family history of cancer, and occupational exposures, none of which are available in the dataset. Because of the de-identified nature of the dataset, individuals in the study cohort cannot be contacted, and thus, no attempts to obtain personal or questionnaire interviews were feasible.

\section{Conclusion}

Recent research suggests that ICS are active as chemopreventive agents for lung cancer. We conducted a populationbased cohort study on patients with adult-onset asthma with a proper person-time approach to determine whether ICS was beneficial. The present study demonstrates that there is no significant association between regular ICS use and future cancer development. However, this cohort study did not consider the patients' socioeconomic status, family history of cancer, and occupational exposures, which may potentially affect the risk estimates.

\section{Acknowledgments}

The authors thank the National Health Research Institute and the Department of the National Health Insurance, Ministry of Health and Welfare, Taiwan for the datasets used in this research.

\section{Disclosure}

The authors report no conflicts of interest in this work.

\section{References}

1. Juniper EF, Kline PA, Vanzieleghem MA, Ramsdale EH, O’Byrne PM, Hargreave FE. Effect of long-term treatment with an inhaled corticosteroid (budesonide) on airway hyperresponsiveness and clinical asthma in nonsteroid-dependent asthmatics. Am Rev Respir Dis. 1990;142(4): 832-836.

2. Oosterhoff Y, Overbeek SE, Douma R, et al. Lower leukotriene C(4) levels in bronchoalveolar lavage fluid of asthmatic subjects after 2.5 years of inhaled corticosteroid therapy. Mediators Inflamm. 1995;4(6): 426-430

3. Sin DD, Man SF, Marciniuk DD, et al. The effects of fluticasone with or without salmeterol on systemic biomarkers of inflammation in chronic obstructive pulmonary disease. Am J Respir Crit Care Med. 2008; 177(11):1207-1214.

4. Rüdiger JJ, Gencay M, Yang JQ, Bihl M, Tamm M, Roth M. Fast beneficial systemic anti-inflammatory effects of inhaled budesonide and formoterol on circulating lymphocytes in asthma. Respirology. 2013; 18(5):840-847. 
5. Wattenberg LW, Wiedmann TS, Estensen RD, Zimmerman CL, Steele VE, Kelloff GJ. Chemoprevention of pulmonary carcinogenesis by aerosolized budesonide in female A/J mice. Cancer Res. 1997;57(24): 5489-5492.

6. Lam S, leRiche JC, McWilliams A, et al. A randomized phase IIb trial of pulmicort turbuhaler (budesonide) in people with dysplasia of the bronchial epithelium. Clin Cancer Res. 2004;10(19):6502-6511.

7. Veronesi G, Szabo E, Decensi A, et al. Randomized phase II trial of inhaled budesonide versus placebo in high-risk individuals with CT screen-detected lung nodules. Cancer Prev Res (Phila). 2011;4(1): 34-42.

8. Parimon T, Chien JW, Bryson CL, McDonell MB, Udris EM, Au DH. Inhaled corticosteroids and risk of lung cancer among patients with chronic obstructive pulmonary disease. Am J Respir Crit Care Med. 2007;175(7):712-719.

9. Kiri VA, Fabbri LM, Davis KJ, Soriano JB. Inhaled corticosteroids and risk of lung cancer among COPD patients who quit smoking. Respir Med. 2009;103(1):85-90.

10. Sohal SS, Soltani A, Reid D, et al. A randomized controlled trial of inhaled corticosteroids (ICS) on markers of epithelial-mesenchymal transition (EMT) in large airway samples in COPD: an exploratory proof of concept study. Int J Chron Obstruct Pulmon Dis. 2014;9:533-542.

11. Lee CH, Hyun MK, Jang EJ, Lee NR, Kim K, Yim JJ. Inhaled corticosteroid use and risks of lung cancer and laryngeal cancer. Respir Med. 2013;107(8):1222-1233.

12. Camargo CA Jr, Barr RG, Chen R, Speizer FE. Prospective study of inhaled corticosteroid use, cardiovascular mortality, and all-cause mortality in asthmatic women. Chest. 2008;134(3):546-551.

13. Amelink M, de Nijs SB, de Groot JC, et al. Three phenotypes of adultonset asthma. Allergy. 2013;68(5):674-680.

14. de Nijs SB, Venekamp LN, Bel EH. Adult-onset asthma: is it really different? Eur Respir Rev. 2013;22(127):44-52.

15. Assimes TL, Suissa S. Immortal person time bias in pharmacoepidemiological studies of antihypertensive drugs. Am J Cardiol. 2011;108(6):902-903.

16. Suissa S. Effectiveness of inhaled corticosteroids in chronic obstructive pulmonary disease: immortal time bias in observational studies. $\mathrm{Am}$ J Respir Crit Care Med. 2003;168(1):49-53.
17. Suissa S. Inhaled steroids and mortality in COPD: bias from unaccounted immortal time. Eur Respir J. 2004;23(3):391-395.

18. Suissa S. Observational studies of inhaled corticosteroids in chronic obstructive pulmonary disease: misconstrued immortal time bias. Am J Respir Crit Care Med. 2006;173(4):464; author reply 464-465.

19. Suissa S. Immortal time bias in observational studies of drug effects. Pharmacoepidemiol Drug Saf. 2007;16(3):241-249.

20. Gau CS, Chang IS, Lin Wu FL, et al. Usage of the claim database of national health insurance programme for analysis of cisaprideerythromycin co-medication in Taiwan. Pharmacoepidemiol Drug Saf. 2007;16(1):86-95.

21. Kok VC, Horng JT, Chang WS, Hong YF, Chang TH. Allopurinol therapy in gout patients does not associate with beneficial cardiovascular outcomes: a population-based matched-cohort study. PloS One. 2014;9(6):e99102.

22. Kok VC, Horng JT, Huang JL, et al. Population-based cohort study on the risk of malignancy in East Asian children with Juvenile idiopathic arthritis. BMC Cancer. 2014;14:634.

23. Kok VC, Horng JT, Lin HL, Chen YC, Chen YJ, Cheng KF. Gout and subsequent increased risk of cardiovascular mortality in non-diabetics aged 50 and above: a population-based cohort study in Taiwan. BMC Cardiovasc Disord. 2012;12:108.

24. Kelly HW. Comparison of inhaled corticosteroids: an update. Ann Pharmacother. 2009;43(3):519-527.

25. Hosmer DW, Lemeshow S. Confidence interval estimation of interaction. Epidemiology. 1992;3(5):452-456.

26. Shaya FT, Maneval MS, Gbarayor CM, et al. Burden of COPD, asthma, and concomitant COPD and asthma among adults: racial disparities in a medicaid population. Chest. 2009;136(2):405-411.

27. Mannino DM. Coexisting asthma and COPD: confused clinicians or poor prognosticator? Chest. 2008;134(1):1-2.

28. Torén K, Ekerljung L, Kim JL, et al. Adult-onset asthma in west Sweden - incidence, sex differences and impact of occupational exposures. Respir Med. 2011;105(11):1622-1628.

29. Sood A, Qualls C, Schuyler M, et al. Adult-onset asthma becomes the dominant phenotype among women by age 40 years. The longitudinal CARDIA study. Ann Am Thorac Soc. 2013;10(3):188-197. 


\section{Supplementary material}

Table SI Comparison of the incidence density of cancer for ICS regular users and non-ICS users by different characteristics and the IRR

\begin{tabular}{|c|c|c|c|c|c|c|c|}
\hline \multirow[t]{2}{*}{ Characteristics } & \multicolumn{4}{|c|}{ ICS regular users } & \multicolumn{3}{|c|}{ Non-ICS ${ }^{a}$ users } \\
\hline & $(n=2,1 \mid 7)$ & Cancer PY & Rate $^{\mathrm{b}}$ & IRR (95\% Cl) & $(n=17,732)$ & Cancer PY & Rate $^{\mathrm{b}}$ \\
\hline$\overline{\text { All }}$ & 130 & $7,364.96$ & 17.7 & $1.22(1.02-1.47)$ & $\mathrm{I}, 064$ & $73,788.86$ & 14.4 \\
\hline \multicolumn{8}{|l|}{ Age group (years) } \\
\hline $20-39$ & 7 & $2,025.22$ & 3.5 & $0.85(0.39-1.83)$ & 80 & $19,569.69$ & 4.1 \\
\hline $40-59$ & 38 & $2,547.68$ & 14.9 & $1.33(0.95-1.87)$ & 285 & $25,432.89$ & 11.2 \\
\hline $60-79$ & 76 & $2,479.38$ & 30.7 & $1.27(1.00-1.61)$ & 575 & $23,847.05$ & 24.1 \\
\hline$\geq 80$ & 9 & 312.68 & 28.8 & $1.15(0.58-2.26)$ & 124 & $4,939.23$ & 25.1 \\
\hline \multicolumn{8}{|l|}{ Sex } \\
\hline Male & 79 & $3,669.51$ & 21.5 & $1.20(0.95-1.52)$ & 602 & $33,528.92$ & 18.0 \\
\hline Female & 51 & $3,695.45$ & 13.8 & $1.20(0.90-1.61)$ & 462 & $40,259.94$ & 11.5 \\
\hline \multicolumn{8}{|l|}{$\mathrm{CCl}$ group } \\
\hline $\mathrm{CCl}$ score 0 & 43 & $3,774.65$ & II.4 & I.0I (0.73-I.38) & 426 & $37,592.66$ & 11.3 \\
\hline $\mathrm{CCl}$ score I, 2 & 69 & $3,004.84$ & 23.0 & $1.36(1.06-1.75)$ & 500 & $29,566.91$ & 16.9 \\
\hline $\mathrm{CCl}$ score 3,4 & 15 & 495.89 & 30.2 & $1.46(0.85-2.50)$ & 115 & $5,557.48$ & 20.7 \\
\hline $\mathrm{CCl}$ score $\geq 5$ & 3 & 89.58 & 33.5 & $1.56(0.47-5.20)$ & 23 & $|, 07| .8 \mid$ & 21.5 \\
\hline \multicolumn{8}{|l|}{ Comorbidities } \\
\hline \multicolumn{8}{|l|}{ Allergic rhinitis } \\
\hline No & 72 & $3,711.16$ & 19.4 & $1.25(0.98-1.59)$ & 785 & $50,591.92$ & 15.5 \\
\hline Yes & 58 & $3,653.81$ & 15.9 & $1.32(0.99-1.75)$ & 279 & $23,196.94$ & 12.0 \\
\hline \multicolumn{8}{|c|}{ Atopic dermatitis } \\
\hline No & 120 & $6,944.35$ & 17.3 & $1.21(1.00-1.46)$ & $\mathrm{I}, 007$ & $70,444.21$ & 14.3 \\
\hline Yes & 10 & 420.61 & 23.8 & $1.40(0.7 \mid-2.73)$ & 57 & $3,344.65$ & 17.0 \\
\hline \multicolumn{8}{|l|}{ COPD } \\
\hline No & 26 & $3,202.63$ & 8.1 & $0.68(0.46-1.01)$ & 551 & $46,100.24$ & 12.0 \\
\hline Yes & 104 & $4,162.33$ & 25.0 & 1.35 (1.09-1.67) & 513 & $27,688.62$ & 18.5 \\
\hline \multicolumn{8}{|c|}{ Diabetes mellitus } \\
\hline No & 102 & $6,176.01$ & 16.5 & 1.24 (I.0I-I.52) & 820 & $61,352.54$ & 13.4 \\
\hline Yes & 28 & $\mathrm{I}, \mathrm{I} 88.96$ & 23.6 & $1.20(0.81-1.77)$ & 244 & $12,436.32$ & 19.6 \\
\hline \multicolumn{8}{|l|}{ Hypertension } \\
\hline No & 60 & $4,503.63$ & 13.3 & $1.27(0.97-1.66)$ & 484 & $46,113.02$ & 10.5 \\
\hline Yes & 70 & $2,861.33$ & 24.5 & $1.17(0.91-1.50)$ & 580 & $27,675.84$ & 21.0 \\
\hline \multicolumn{8}{|l|}{ Depression } \\
\hline No & 125 & $7,273.93$ & 17.2 & $1.19(0.99-1.43)$ & $|, 05|$ & $72,757.90$ & 14.4 \\
\hline Yes & 5 & 91.04 & 54.9 & $4.36(1.55-12.2)$ & 13 & $1,030.96$ & 12.6 \\
\hline \multicolumn{8}{|l|}{ GERD } \\
\hline No & 129 & $7,311.10$ & 17.6 & $1.22(1.02-1.47)$ & 1,062 & $73,617.95$ & 14.4 \\
\hline Yes & I & 53.86 & 18.6 & $1.59(0.14-17.5)$ & 2 & |70.9| & 11.7 \\
\hline \multicolumn{8}{|l|}{ Osteoporosis } \\
\hline No & 125 & $7,139.83$ & 17.5 & $1.22(1.01-1.47)$ & $\mathrm{I}, 024$ & $71,470.03$ & 14.3 \\
\hline Yes & 5 & 225.13 & 22.2 & $1.29(0.5 \mathrm{I}-3.26)$ & 40 & $2,3 \mid 8.83$ & 17.3 \\
\hline \multicolumn{8}{|l|}{ Heart failure } \\
\hline No & 105 & $6,738.45$ & 15.6 & $1.12(0.91-1.37)$ & 955 & $68,580.29$ & 13.9 \\
\hline Yes & 25 & 626.52 & 39.9 & $1.91(1.23-2.94)$ & 109 & $5,208.57$ & 20.9 \\
\hline \multicolumn{8}{|l|}{ Dyslipidemia } \\
\hline No & 104 & $6,503.08$ & 16.0 & $1.15(0.94-1.4 I)$ & 907 & $65,118.64$ & 13.9 \\
\hline Yes & 26 & 861.88 & 30.2 & $1.67(1.10-2.52)$ & 157 & $8,670.22$ & 18.1 \\
\hline \multicolumn{8}{|l|}{ Rhinosinusitis } \\
\hline No & 121 & $6,915.24$ & 17.5 & $1.21(1.00-1.46)$ & $\mathrm{I}, 025$ & $70,843.45$ & 14.5 \\
\hline Yes & 9 & 449.72 & 20.0 & $1.51(0.73-3.12)$ & 39 & $2,945.41$ & 13.2 \\
\hline \multicolumn{8}{|c|}{ Cardiac arrhythmia } \\
\hline No & 96 & $6,450.24$ & 14.9 & $1.09(0.89-1.35)$ & 889 & $65,254.08$ & 13.6 \\
\hline Yes & 34 & 914.73 & 37.2 & $1.81(1.26-2.62)$ & 175 & $8,534.78$ & 20.5 \\
\hline
\end{tabular}


Table SI (Continued)

\begin{tabular}{|c|c|c|c|c|c|c|c|}
\hline \multirow[t]{2}{*}{ Characteristics } & \multicolumn{4}{|c|}{ ICS regular users } & \multicolumn{3}{|c|}{ Non-ICS ${ }^{a}$ users } \\
\hline & $(n=2,117)$ & Cancer PY & Rate $^{\text {b }}$ & IRR (95\% CI) & $(n=17,732)$ & Cancer PY & Rate $^{\mathrm{b}}$ \\
\hline \multicolumn{8}{|l|}{ Coronary heart } \\
\hline \multicolumn{8}{|l|}{ disease } \\
\hline No & 76 & $5,896.31$ & 12.9 & $1.03(0.8 \mathrm{I}-1.30)$ & 736 & $58,698.69$ & 12.5 \\
\hline Yes & 54 & $1,468.66$ & 36.8 & $1.69(1.27-2.26)$ & 328 & $15,090.17$ & 21.7 \\
\hline \multicolumn{8}{|l|}{ Follow-up (years) } \\
\hline$<1$ & 33 & 186.46 & 177.0 & $0.68(0.48-0.98)$ & 354 & $1,368.30$ & 258.7 \\
\hline $1-3$ & 48 & $1,221.66$ & 39.3 & $0.94(0.69-1.26)$ & 371 & $8,838.15$ & 42.0 \\
\hline $3-5$ & 34 & $2,395.81$ & 14.2 & I.I3 (0.79-I.63) & 218 & $|7,4| \mid .47$ & 12.5 \\
\hline $5-7$ & 14 & $2,565.44$ & 5.5 & $1.32(0.76-2.31)$ & 108 & $26,183.84$ & 4.1 \\
\hline$>7$ & I & 995.60 & 1.0 & $1.54(0.20-11.8)$ & 13 & $19,987.10$ & 0.7 \\
\hline \multicolumn{8}{|c|}{ Other asthma medication } \\
\hline LABA & 79 & $4,427.38$ & 17.8 & $1.05(0.15-7.52)$ & I & 58.61 & 17.1 \\
\hline SABA & 23 & $1,1 \mid 4.21$ & 20.6 & $1.21(0.68-2.14)$ & 24 & $1,405.18$ & 17.1 \\
\hline LTRA & 12 & $\mathrm{I}, 048.86$ & $\mathrm{II} .4$ & $1.21(0.50-2.97)$ & 8 & 848.70 & 9.4 \\
\hline Theophylline & 94 & $4,4 \mid 7.33$ & 21.3 & 1.43 (1.15-I.78) & 510 & $34,296.29$ & 14.9 \\
\hline OCS & 25 & $\mathrm{I}, 486.65$ & 16.8 & $1.17(0.76-1.79)$ & 127 & $8,8 \mid 8.54$ & 14.4 \\
\hline \multicolumn{8}{|c|}{ Smoking-related diagnoses } \\
\hline Yes & 80 & $2,666.50$ & 30.0 & 1.34 (I.04-I.7I) & 303 & $13,490.45$ & 22.5 \\
\hline No & 50 & $4,698.46$ & 10.6 & $0.84(0.63-1.12)$ & 761 & $60,298.41$ & 12.6 \\
\hline
\end{tabular}

Notes: ${ }^{a}$ Referent group. 'Incidence rate, per I,000 PY. Values shown in bold are statistically significant.

Abbreviations: $\mathrm{CCl}$, Charlson comorbidity index; CI, confidence interval; COPD, chronic obstructive pulmonary disease; GERD, gastroesophageal reflux; ICS, inhaled corticosteroids; IRR, incidence rate ratio; LABA, long-acting beta ${ }_{2}$-agonists; LTRA, leukotriene receptor antagonists; OCS, oral corticosteroids; PY, person-years; SABA, inhaled short-acting beta ${ }_{2}$-agonists.

\section{Publish your work in this journal}

Therapeutics and Clinical Risk Management is an international, peerreviewed journal of clinical therapeutics and risk management, focusing on concise rapid reporting of clinical studies in all therapeutic areas, outcomes, safety, and programs for the effective, safe, and sustained use of medicines. This journal is indexed on PubMed Central, CAS,
EMBase, Scopus and the Elsevier Bibliographic databases. The manuscript management system is completely online and includes a very quick and fair peer-review system, which is all easy to use. Visit http://www.dovepress.com/testimonials.php to read real quotes from published authors.

Submit your manuscript here: http://www.dovepress.com/therapeutics-and-clinical-risk-management-journal 